\title{
Differential Nutrient Uptake and Its Transport in Tomato Plants on Different Fertilizer Regimens
}

\author{
Takafumi Kinoshita ${ }^{1,2}$ \\ National Agricultural Research Center for Western Region (WeNARC), National \\ Agriculture and Food Research Organization (NARO), Sen-yucho 1-3-1, \\ Zentsuji, Kagawa, 765-8508, Japan
}

\author{
Masaharu Masuda \\ Okayama University Graduate School of Natural Science and Technology, \\ Tsushima-naka 1-1-1, Kita-ku, Okayama, 700-8530, Japan
}

Additional index words. capillary watering, controlled-release fertilizer, nutrient utilization efficiency, Solanum lycopersicum, subirrigation

\begin{abstract}
Application of controlled-release fertilizer (CRF) to a root-proof capillary wick irrigation system (a type of subirrigation method) has both economical and environmental benefits, because it does not require any equipment for fertigation and minimizes water leaching. In this study, we examined the effects of CRF and liquid fertilizer (LF), a conventional fertigation method, on fruit production and nutrient uptake and transport in forcing tomato cultures for harvesting $\mathbf{1 5}$ trusses per plant from October to June. No significant difference was noted in marketable fruit yield between CRF- and LF-treated plants. The quantity of nutrient uptake per plant and per fruit yield was lower with CRF than with LF, indicating that nutrients were used more efficiently for fruit production in plants grown with CRF. Analysis of the volume and mineral concentrations of xylem exudates indicated that the amount of nutrients absorbed was greater with LF than with CRF, particularly after the tenth truss was harvested. Mineral concentrations in the substrate solution of CRF-treated plants were initially higher than those in the substrate solution of LF-treated plants but extremely low after the second truss was harvested, whereas mineral concentrations in the xylem exudates were similar in CRF and LF plants until the eighth truss was harvested. Thus, the difference in mineral concentrations between the xylem exudates and substrate solution was much larger in the case of CRF than in the case of LF, indicating that the plants absorbed the bulk of nutrients immediately after their release from the CRF surface. Therefore, CRF is suitable in this system, because it combines high fruit production with high nutrient utilization efficiency.
\end{abstract}

Efficient nutrient use in greenhouse vegetable production is essential for both economic and environmental reasons. In general, nutrient and water utilization efficiency is higher with subirrigation than with drip irrigation, because subirrigation greatly reduces water leaching (Goodwin et al., 2003; Incrocci et al., 2006; Santamaria et al., 2003). For uniform water distribution in potted ornamental plants, capillary wick irrigation, a subirrigation method, has become popular in Japan since the 1980s. It eliminates the need for irrigation equipment, because it uses capillary forces. This simple method is also labor-efficient and economical. However, for long-term cultivation, capillary wick irrigation is unpopular, because it results in a lower fruit yield. This occurs because

\footnotetext{
Received for publication 3 Mar. 2011. Accepted for publication 25 June 2011.

We thank the technical support staff of the National Agricultural Center for Western Region for helping with the measurements and the crop management in this study.

${ }^{1}$ Graduate student of Okayama University.

${ }^{2}$ To whom reprint requests should be addressed; e-mail takino@affrc.go.jp.
}

roots penetrate the wick and decrease capillary action. To solve this problem, Masuda (2008) developed a root-proof capillary wick irrigation system for long-term vegetable production by making the wick impenetrable to the roots. In this irrigation system, water is stably supplied by capillary action from the side of the substrate without root invasion into the wick. Subsequent research focused on determining a suitable nutrient concentration for the fertilizer solution to improve tomato cultivation using this system (Masuda and Fukumoto, 2008; Morishige et al., 2009a, 2009b).

Compared with LF, CRF is economical, because it does not require equipment for adjustment of nutrient concentration and fertilizer delivery. In our previous study, we established that for harvesting 15 trusses, the optimal nitrogen supply is $16.2 \mathrm{~g}$ per plant (Kinoshita et al., 2010a, 2010b) if the timing of nutrient release from the CRF was optimized and that nutrient utilization efficiency was higher with CRF than with LF (Kinoshita et al., 2010b).

Therefore, further investigations were necessary to optimize nutrient application with CRF, because fruit yield from the upper trusses was still lower with CRF than with LF (Kinoshita et al., 2010b). In particular, fertilizer combinations needed to be optimized to ensure an adequate supply of nutrients during the later growth stages.

Furthermore, mineral concentrations in the substrate solutions were extremely low after the first half of the experiment with CRF application (Kinoshita et al., 2010a, 2010b). Imano et al. (2011) have also reported that the electrical conductivity (EC) of the substrate solution is very low after the first half of the growth period with CRF application. These results indicate that plants absorb the bulk of nutrients immediately after release from the CRF surface, which translates into high nutrient utilization efficiency with respect to fruit production.

Therefore, we investigated the differences in the modes of nutrient uptake in CRF- and LFtreated plants. Xylem exudates were analyzed after stem decapitation to assess nutrient uptake by the plant. The volume of xylem exudates per unit of time can be used to measure the activity of water uptake (Yamaguchi et al., 1995). On the other hand, the mineral concentrations in xylem exudates within $1 \mathrm{~h}$ after stem decapitation reflect mineral transport in intact plants, because the concentration remains fairly constant during this time (Armstrong and Kirkby, 1979; Masuda, 1989; Masuda and Gomi, 1982; Widders and Lorenz, 1982). Furthermore, some studies have shown that the nutrient uptake capacity of roots can be measured using volume and mineral concentrations of xylem exudates (Ho et al., 1993; Ma et al., 2005; Noguchi et al., 2005; Sakaigaichi et al., 2005, 2007). Therefore, in this study, xylem exudates were analyzed during the first hour after stem decapitation to assess nutrient transport and uptake.

The aim of this study was to examine fruit production in plants treated with CRF-modified combinations of fertilizers and to determine the difference between CRF and LF with respect to nutrient utilization efficiency for fruit production and seasonal nutrient uptake by plants.

\section{Materials and Methods}

Plant material and growth conditions. The research was conducted in the plastic greenhouse (area, $252 \mathrm{~m}^{2}$ ) at the National Agricultural Research Center for Western Region, Zentsuji, Kagawa, Japan (lat. $34^{\circ} 13^{\prime}$ N, long. $133^{\circ} 46^{\prime} \mathrm{E}$ ). Seeds of large-fruit tomato plants, 'House Momotaro' (Takii Seed Co., Kyoto, Japan), were sown in 128-well plug trays filled with commercial growth medium (Metro-Mix 350; Sun Gro Horticulture Distribution Inc., British Columbia, Canada) on 11 Sept. 2009. Seedlings were transferred to 9-cm polyethylene pots filled with a mixed substrate [paddy soil:bark compost:perlite:peatmoss, 2:4:1:1 $(\mathrm{v} / \mathrm{v})]$ on 1 Oct. 2009. This substrate is reported to be suitable for the root-proof wick irrigation system (Kinoshita and Masuda, 2011). On 20 Oct. 2009, 39-d-old seedlings were transplanted at a plant density of 2.8 plants $/ \mathrm{m}^{2}$ into the root-proof wick irrigation system (Fig. 1) containing the same substrate (3 L per plant). Plastic boxes $(39 \mathrm{~cm}$ long $\times 22 \mathrm{~cm}$ wide $\times 16$ $\mathrm{cm}$ high) were used with two plants per box. 
The distance between plants was $20 \mathrm{~cm}$. The plastic boxes were arranged in rows from south to north. Thirty plastic boxes were placed in each row, and the distance between the rows was $1.8 \mathrm{~m}$. Each plant was allocated one wick ( $45 \mathrm{~cm}$ long $\times 4 \mathrm{~cm}$ wide). The substrate surface was covered with rice husks to prevent evaporation. As the plants grew, all lateral shoots were removed, and the remaining single stem was trained vertically on a string attached to a horizontal wire at a height of $2.5 \mathrm{~m}$. The flowering trusses were treated with 15 ppm parachlorphenoxyacetic acid to promote fruit set. Trusses were thinned to contain no more than five fruits. On 1 May 2010, plants were topped with two leaves retained above the 15th truss. Fruit harvesting was initiated on 19 Jan. and continued until 29 June 2010. The greenhouse was heated at night to maintain a minimum temperature of $13{ }^{\circ} \mathrm{C}$, and ventilation was initiated for daytime temperatures higher than $28^{\circ} \mathrm{C}$. Air and substrate temperatures inside the greenhouse were measured and 10-min averages were recorded using a data logger (ZR-RX40V; OMRON Corp., Kyoto, Japan). Solar radiation outside the greenhouse was measured every $10 \mathrm{~s}$ with a pyrheliometer (MS-802; EKO Instruments Co. Ltd., Tokyo, Japan) and integrated every $1 \mathrm{~h}$.

Treatments. Plants were supplied with CRF or LF. The nutrient composition of CRF was determined from our previous results (Kinoshita et al., 2010a, 2010b), and nutrient release from

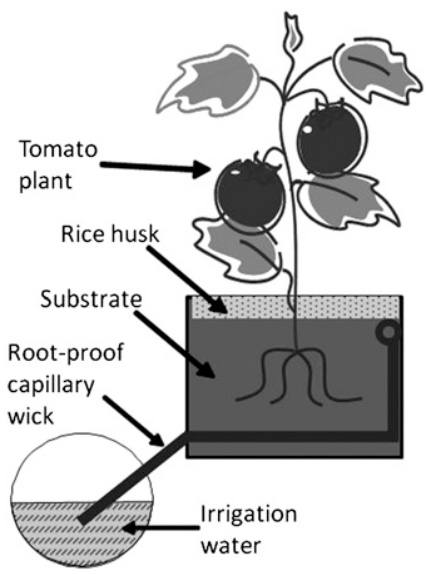

Fig. 1. Diagram of the root-proof wick irrigation system used in the experiment.
CRF was simulated using nutrient release simulation software (Sehi-meijin Version 2.0; JA Zen-noh, Tokyo, Japan). The nutrient components of CRF are shown in Table 1. The nitrogen supply ratio of $\mathrm{NO}_{3}-\mathrm{N}: \mathrm{NH}_{4}-\mathrm{N}$ was 76:24. Ash of chicken droppings was applied to adjust $\mathrm{pH}$ and to supply macro- and microminerals, except nitrogen. All fertilizers were mixed with the substrate before planting. A half-strength commercial nutrient solution with an EC of $1.4 \mathrm{dS} \cdot \mathrm{m}^{-1}$ (Otsuka Chemical Co. Ltd., Osaka, Japan) and containing nitrogen (N) $\left(\mathrm{NO}_{3}-\mathrm{N}: \mathrm{NH}_{4}-\mathrm{N}=9: 1\right)$, phosphorus $(\mathrm{P})$, potassium $(\mathrm{K})$, calcium $(\mathrm{Ca})$, and magnesium $(\mathrm{Mg})$ at concentrations of $130,26,168,82$, and $18 \mathrm{mg} \cdot \mathrm{L}^{-1}$, respectively, was applied to the plants as LF. The experimental design was a randomized complete block with three replications. Each block was placed in each row. Each elementary plot comprised 30 plants.

Measurements of plant growth and fruit yield. Individual mature fruits of eight plants were harvested from each plot once a week, and the fresh weight of each fruit was measured. Marketable fruit was defined as fruit weighing over $80 \mathrm{~g}$ with no physiological damage. The fruit Brix was measured using a digital refractometer (PAL-1; ATAGO Co., Ltd., Tokyo, Japan). As an indicator of plant growth, the diameter of the stem below each fruit truss was measured for six plants from each plot at the end of the experiment. The various parts of four plants (i.e., leaves, stem, and fruits) from each plot were separated. The plant parts were dried in an open-air oven at $80^{\circ} \mathrm{C}$ for 1 week and measured. The parts were ground into a powder, and the total $\mathrm{N}$ content of the dried plants was measured using a NC analyzer (Vario MAX CN; Elementar Analysensysteme, Germany). After wet digestion of the dried plants, $\mathrm{P}$ concentration was measured using the vanadomolybdophosphoric yellow color method; $\mathrm{K}, \mathrm{Ca}$, and $\mathrm{Mg}$ concentrations were measured using inductively coupled plasma atomic emission spectroscopy (SPS-1500NR; Seiko Instrument Inc., Chiba, Japan).

Measurement of nutrients in substrate solution and xylem exudates. Substrate solution was collected at 2-week intervals from two spots, which were at $5-\mathrm{cm}$ depth from the soil surface per plot using a soil moisture sampler (DIK-300B; Daiki Rika Kogyo Co. Ltd., Saitama, Japan). Xylem exudates were collected at 4-week intervals on sunny days from plants in each plot. For this purpose, two

Table 1. Fertilizer component concentrations in the substrate with controlled-release fertilizer treatment (gram per plant)

\begin{tabular}{lcccccc}
\hline Japanese standard name of fertilizer & Days $^{z}$ & Nitrogen & Phosphorus & Potassium & Calcium & Magnesium \\
\hline Ash of chicken droppings & - & & 0.9 & 1.5 & 1.6 & 0.4 \\
Eco-long-total 313 & 140 & 4.7 & 1.7 & 3.9 & & 0.4 \\
Super-eco-long & 100 & 3.1 & 1.1 & 2.6 & & \\
Long-calcium nitrate & 140 & 7.4 & & & 10.2 \\
Coating potassium & 180 & 1.0 & & 15.8 & & 1.4 \\
Long-magnesium sulfate & 180 & & & & \\
& Total & 16.2 & 3.8 & 23.7 & 11.9 & 2.2 \\
\hline
\end{tabular}

${ }^{\mathrm{z} N u m b e r}$ of days until $80 \%$ of the amount is released at $25^{\circ} \mathrm{C}$.

${ }^{\mathrm{y}}$ This fertilizer contained nitrogen, phosphorus, potassium, and magnesium in the ratio 13:4.8:10.8:1.2, besides small amounts of micronutrients.

${ }^{\mathrm{x}}$ Nutrients are released sigmoidally in contrast to linear nutrient release in other fertilizers. plants from each plot were decapitated at $5 \mathrm{~cm}$ above the ground at $1000 \mathrm{HR}$. The first few drops of exudates were discarded, and the exudates were collected in a vial for $1 \mathrm{~h}$. The samples were stored at $-20{ }^{\circ} \mathrm{C}$ until analysis. The EC values of the substrate solutions were measured using an EC meter (B-173; HORIBA, Ltd., Kyoto, Japan). Concentrations of $\mathrm{NO}_{3}-\mathrm{N}$, $\mathrm{NH}_{4}-\mathrm{N}, \mathrm{PO}_{4}-\mathrm{P}, \mathrm{K}, \mathrm{Ca}$, and $\mathrm{Mg}$ in the substrate solutions and exudates were determined by ion chromatography (DX-AQ; Nippon Dionex K.K., Osaka, Japan).

Data analysis. Analysis of variance was carried out using the statistical software (Microsoft Office Excel 2007; Microsoft Co., Redmond, WA).

\section{Results}

Climatic conditions during the experiment. Climatic conditions during the experiment are shown in Figure 2. The mean daily air temperatures, substrate temperatures, and mean 5 -d solar radiation for the entire experimental period were $17.3,17.7$, and $12.3 \mathrm{~mJ} \cdot \mathrm{m}^{-2} \cdot \mathrm{d}^{-1}$, respectively. Mean daily air and substrate temperatures were highest at the end of June and lowest in mid-January. Mean 5-d solar radiation was highest at the end of May and lowest in mid-January.

Plant growth, fruit yield, and quality. The stem diameters of the third truss measured at the end of the experiment were greater in the CRF plants than in the LF plants. The diameters of the ninth truss were smaller in the CRF plants than in the LF plants (data not shown). The total and marketable fruit yields from the CRF- and LF-treated plants were not significantly different (Table 2 ). The soluble solids concentration was higher, and shoot and total dry weight was lower in the CRF than in the LF plants.

Nutrient content and uptake. Nutrient content in shoots was significantly lower with CRF than with LF, except for N (Table 3). Concentrations of $\mathrm{K}$ and $\mathrm{Ca}$ were significantly lower in CRF fruits than in LF fruits. For each element, nutrient uptake per plant and per kilogram fruit production was higher with LF than with CRF. Therefore, nutrient utilization efficiency for fruit production was better with CRF than with LF.

Inorganic nutrient concentrations in substrate solution. The EC values of the substrate solutions measured during the experiment are shown in Figure 3. For CRF, the EC value of the substrate solution was $\approx 2.5 \mathrm{dS} \cdot \mathrm{m}^{-1}$ at the beginning of November and decreased gradually to $\approx 0.5 \mathrm{dS} \cdot \mathrm{m}^{-1}$. In the case of the $\mathrm{LF}$, the $\mathrm{EC}$ value was $\approx 0.8 \mathrm{dS} \cdot \mathrm{m}^{-1}$ at the beginning of November and increased gradually to $\approx 2.5$ $\mathrm{dS} \cdot \mathrm{m}^{-1}$. After fruit harvesting had begun in January, the EC values for the CRF treatment were significantly lower than those for the LF treatment. Inorganic mineral concentrations of the substrate solutions are shown in Figure 4. The concentrations of $\mathrm{NO}_{3}-\mathrm{N}, \mathrm{K}, \mathrm{Ca}$, and $\mathrm{Mg}$ were significantly higher in the CRF substrates than in the LF substrates at the beginning of the experiment and significantly lower at the first truss fruit harvesting and later growth stages. 


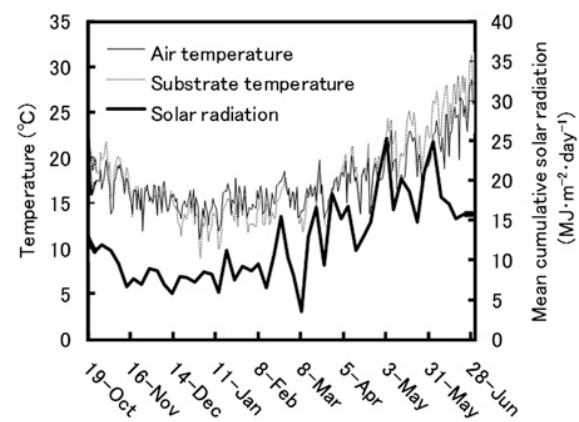

Fig. 2. Mean daily air and substrate temperatures inside the greenhouse and mean 5-d solar radiation outside the greenhouse.
The $\mathrm{NH}_{4}-\mathrm{N}$ concentration remained significantly higher in the CRF substrate until January and then decreased considerably in both the substrates. The $\mathrm{PO}_{4}-\mathrm{P}$ concentration was lower in the CRF substrate than in the LF substrate throughout the experiment. After the first half of the experiment, the concentration of each of the elements was extremely low in the CRF substrates.

Inorganic nutrient concentrations and volumes of xylem exudates. The volumes of xylem exudates decreased between November (during the flowering stage of the second truss) and March (at the harvesting stage of the fifth truss) and then increased in both of the

Table 2. Fruit yield, soluble solids concentration, and whole dry weight of tomatoes from plants on different fertilizer regimens.

\begin{tabular}{|c|c|c|c|c|c|c|}
\hline \multirow[b]{2}{*}{ Fertilizer type } & \multicolumn{2}{|c|}{ Fruit yield } & \multirow[b]{2}{*}{$\begin{array}{l}\text { Soluble solids } \\
\text { concn }^{2}(\text { Brix \%) }\end{array}$} & \multicolumn{3}{|c|}{ Dry wt } \\
\hline & $\begin{array}{c}\text { Total } \\
\text { (kg/plant) }\end{array}$ & $\begin{array}{c}\text { Marketable } \\
\text { (kg/plant) }\end{array}$ & & Shoot & $\begin{array}{c}\text { Fruit } \\
\text { (g/plant) }\end{array}$ & Total \\
\hline$\overline{\mathrm{CRF}}$ & 8.5 & 8.0 & 6.5 & 265 & 472 & 736 \\
\hline $\mathrm{LF}$ & 8.9 & 8.5 & 6.1 & 306 & 509 & 815 \\
\hline Significance & NS & NS & * & $*$ & NS & $*$ \\
\hline
\end{tabular}

${ }^{\mathrm{z}}$ Values represent the average of all trusses.

NS, *Non-significant or significant at $P \leq 0.05$.

$\mathrm{CRF}=$ controlled-release fertilizer; $\mathrm{LF}=$ liquid fertilizer.

Table 3. Nutrient concentrations and uptake in plants fertilized with CRF or LF.

\begin{tabular}{|c|c|c|c|c|c|c|}
\hline Parameter & Fertilizer type & Nitrogen & Phosphorus & Potassium & Calcium & Magnesium \\
\hline \multirow{3}{*}{$\begin{array}{l}\text { Nutrient concentrations } \\
\text { in shoot }(\%)\end{array}$} & $\mathrm{CRF}$ & 2.85 & 0.58 & 3.67 & 2.30 & 0.47 \\
\hline & $\mathrm{LF}$ & 2.98 & 0.74 & 4.15 & 3.20 & 0.63 \\
\hline & Significance & NS & $*$ & $*$ & $*$ & $*$ \\
\hline \multirow{3}{*}{$\begin{array}{l}\text { Nutrient concentrations } \\
\text { in fruit }(\%)\end{array}$} & $\mathrm{CRF}$ & 1.60 & 0.34 & 2.75 & 0.21 & 0.14 \\
\hline & LF & 1.68 & 0.42 & 3.20 & 0.26 & 0.15 \\
\hline & Significance & NS & NS & $*$ & $*$ & NS \\
\hline \multirow{3}{*}{$\begin{array}{l}\text { Nutrient uptake per } \\
\text { plant }^{\mathrm{z}} \text { (g/plant) }\end{array}$} & $\mathrm{CRF}$ & 15.0 & 3.2 & 22.6 & 7.1 & 1.9 \\
\hline & $\mathrm{LF}$ & 17.7 & 4.3 & 28.4 & 10.6 & 2.6 \\
\hline & Significance & $* *$ & $* *$ & * & $* * *$ & $* * *$ \\
\hline \multirow{3}{*}{$\begin{array}{l}\text { Nutrient utilization } \\
\text { efficiency for fruit } \\
\text { production }^{\mathrm{y}}\left(\mathrm{g} \cdot \mathrm{kg}^{-1}\right)\end{array}$} & CRF & 1.79 & 0.37 & 2.67 & 0.84 & 0.23 \\
\hline & $\mathrm{LF}$ & 1.98 & 0.48 & 3.18 & 1.20 & 0.29 \\
\hline & Significance & $*$ & $*$ & $* *$ & $* *$ & $* *$ \\
\hline
\end{tabular}

${ }^{\mathrm{z}}$ Calculated by multiplying dry weight with nutrient concentrations.

${ }^{\mathrm{y}}$ Calculated as total element uptake by the plant $(\mathrm{g})$ divided by total fruit yield $(\mathrm{kg})$.

NS, *,**,***Non-significant or significant at $P \leq 0.05,0.01$, or 0.001 , respectively.

$\mathrm{CRF}=$ controlled-release fertilizer; $\mathrm{LF}=$ liquid fertilizer.

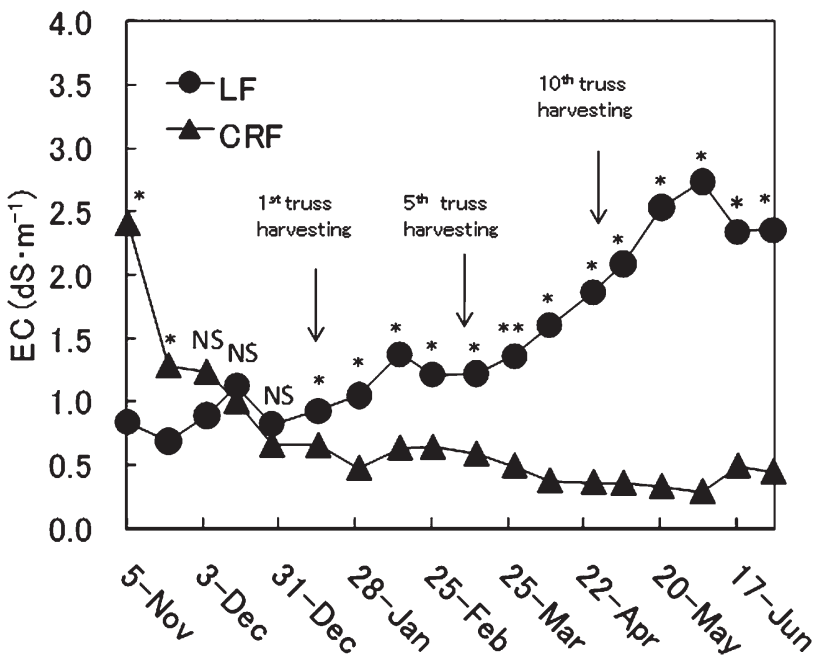

Fig. 3. Electrical conductivity values of the substrate solution throughout the course of the experiment. Ns, *, **Nonsignificant or significant at $P \leq 0.05$ or 0.01 , respectively. treatments (data not shown). The volumes in May and June, after stem topping, were particularly large compared with those in the other periods. Only small differences were noted in the volumes between the CRF and LF treatments throughout the experiment. Inorganic nutrient concentrations of the xylem exudates are shown in Figure 5. Small differences in $\mathrm{NO}_{3}-\mathrm{N}, \mathrm{Ca}$, and $\mathrm{Mg}$ concentrations were observed between the two treatments until March or April, at the harvesting stage of the fifth or seventh truss; however, after April or May, at the harvesting stage of the seventh or the 11th truss, the concentrations were clearly higher in the LF plants than in the CRF plants. $\mathrm{PO}_{4}-\mathrm{P}$ concentrations did not significantly differ between CRF and LF plants throughout the experiment. K concentration was higher in the CRF plants until March and decreased after April. The $\mathrm{NH}_{4}-\mathrm{N}$ concentration was higher in the CRF plants until April and was similar to that in the LF plants after May.

\section{Discussion}

The application of CRF, compared with $\mathrm{LF}$, to this tomato cultivation system enhanced the nutrient utilization efficiency for fruit production (Kinoshita et al., 2010b). However, fruit yield from the upper trusses of the CRF-treated plants was lower than that from the upper trusses of the LF-treated plants (Kinoshita et al., 2010b), suggesting that the amount of fertilizer eluted decreased in the later cultivation period. In this study, we, therefore, compared CRF with LF by using a modified CRF fertilizer combination to optimize nutrient supply. This combination led to similar levels of total fruit production in the $\mathrm{CRF}$ and the LF treatments for the cultivation period from October to June. Furthermore, nutrient utilization efficiency for fruit production was better with CRF, as reported in our previous study (Kinoshita et al., 2010b). High nutrient utilization efficiency in CRF, compared with LF, was attributable to small shoot dry matter and low dry matter nutrient concentration. These results show that the application of CRF can maintain a high level of nutrient utilization efficiency for fruit production by suppressing luxury nutrient uptake. This finding is very significant with respect to fertilizer cost in tomato cultivation.

We examined the volumes and mineral concentrations of xylem exudates to determine the differences in seasonal nutrient uptake between the CRF- and LF-treated plants. The volumes of the xylem exudates were similar in the two groups, indicating similarity in the water uptake capacities of their roots. Differences in the concentrations of minerals in xylem exudates may reflect differences in the nutrient uptake capacity of roots. The volumes of the xylem exudates after stem topping were larger than those before stem topping. In general, higher solar radiation (Masuda and Shimada, 1993; Yamasaki, 2003) and soil temperatures (Yamaguchi et al., 1995) are expected to lead to larger volumes of xylem exudates. The increases in the xylem exudates volumes after stem topping may be caused by the higher 

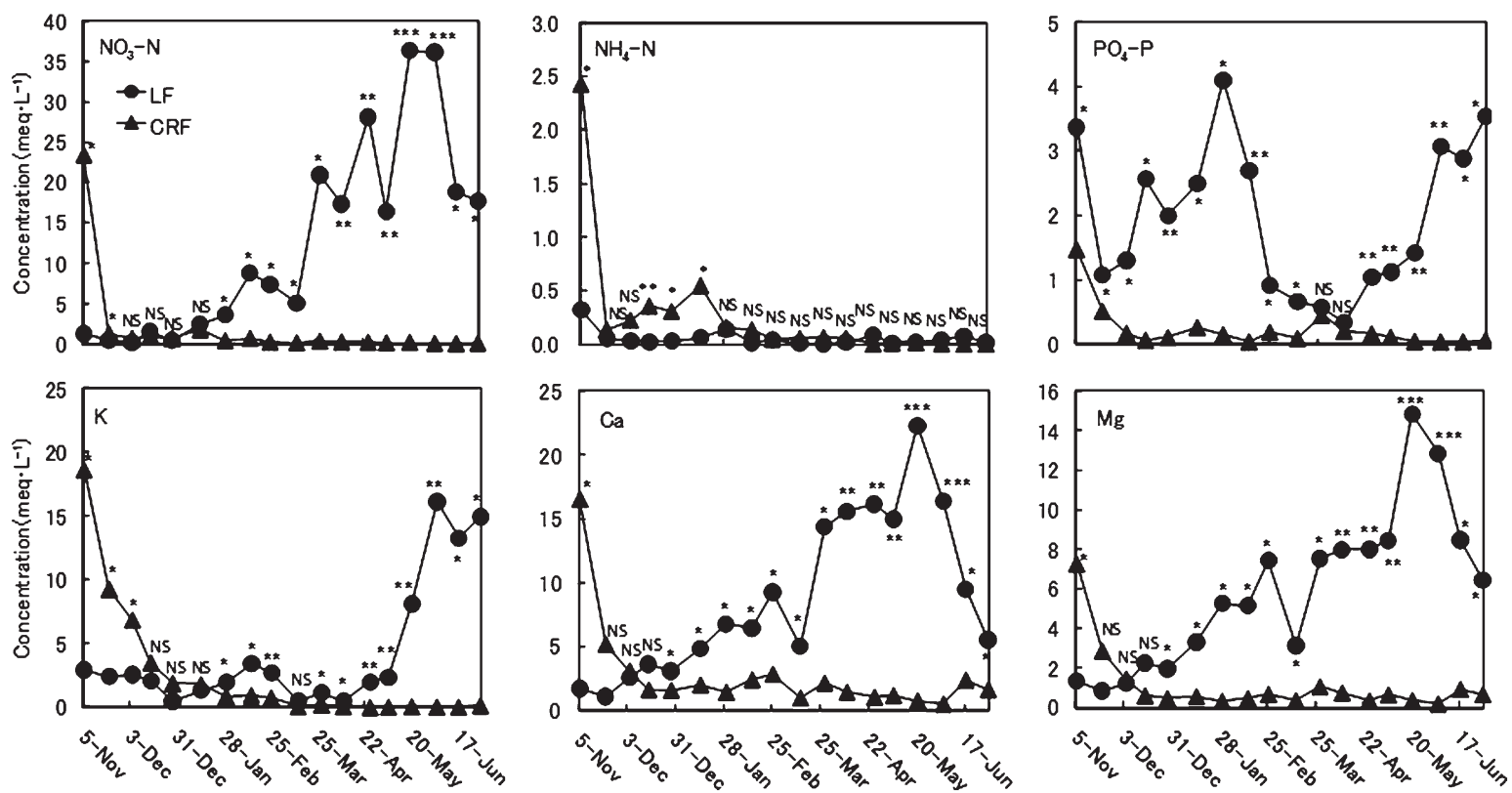

Fig. 4. Inorganic nutrient concentrations in the substrate solution throughout the course of the experiment. Ns, ${ }^{*}, * *, * *$ Nonsignificant or significant at $P \leq 0.05$, 0.01 , or 0.001 , respectively.
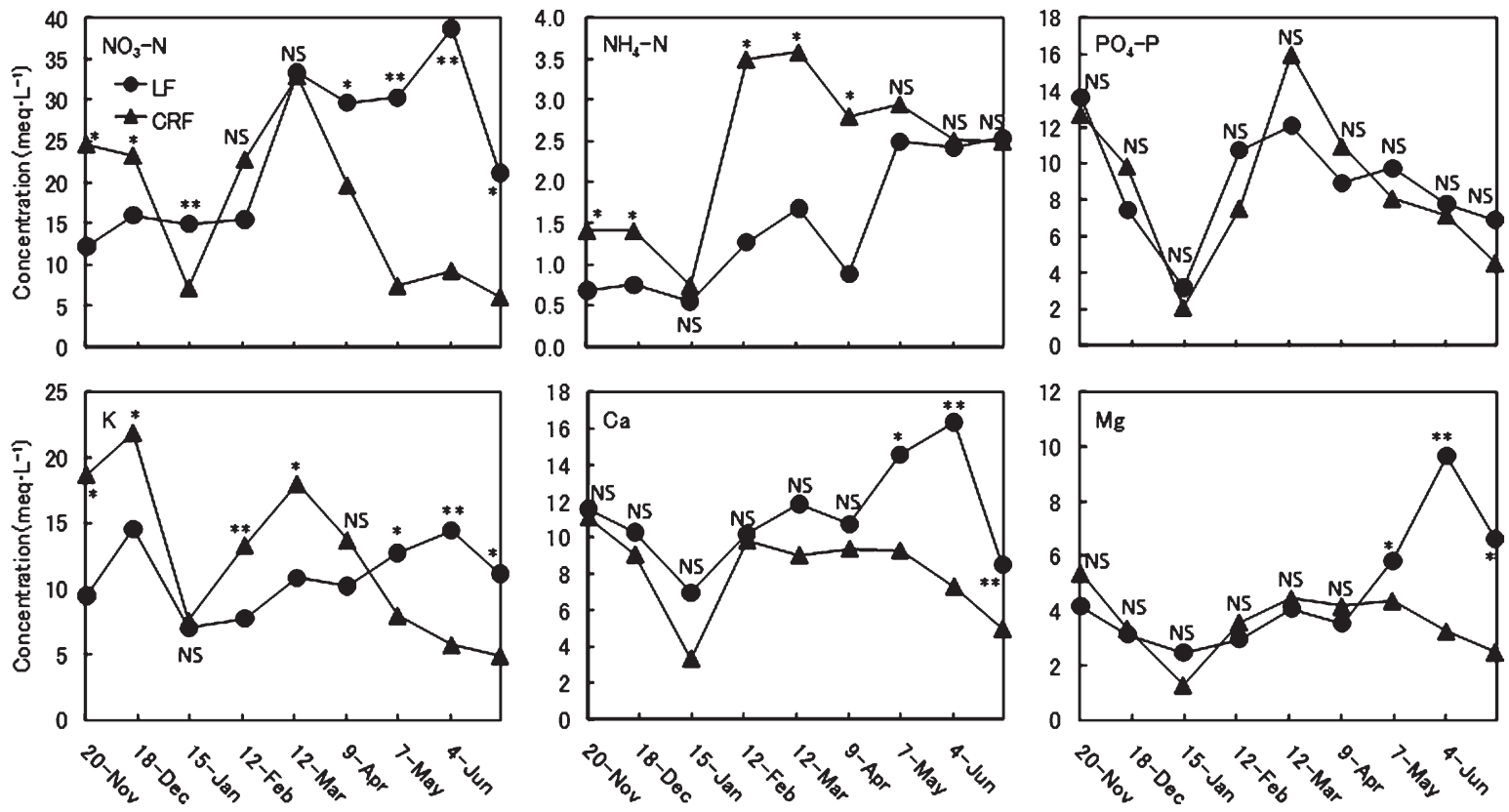

Fig. 5. Inorganic nutrient concentrations in xylem exudates throughout the course of the experiment. Ns, *, **Nonsignificant or significant at $P \leq 0.05$ or 0.01 , respectively.

solar radiation and substrate temperatures during these periods compared with the other periods. The water uptake was also higher during these periods, because the amount of water absorbed by the plant corresponds to the integrated solar radiation, except during the very early growth stages in forcing tomato cultures (Nakano et al., 2010). These facts indicate that the differences in mineral concentrations in the xylem exudates during these periods affected the total nutrient uptake. Consequently, uptake of $\mathrm{NO}_{3}-\mathrm{N}, \mathrm{K}, \mathrm{Ca}$, and $\mathrm{Mg}$ during these periods was much higher in the LF treatment than in the CRF treatment.
The difference in $\mathrm{PO}_{4}-\mathrm{P}$ uptake between the CRF and LF plants cannot be explained by the small differences in the volumes and mineral concentrations of the xylem exudates. In this study, the $\mathrm{PO}_{4}-\mathrm{P}$ concentration of the xylem exudates was unaffected by nutrient concentrations in the substrate. Generally, the phosphate concentration in xylem exudates does not reflect the total amount of $\mathrm{P}$ present in the rhizosphere (Noguchi et al., 2005; Tachibana and Suzuki, 1980). On the other hand, Terabayashi et al., (1991a, 1991b) reported that the ratio of uptake during the night to the 24-h uptake for $\mathrm{PO}_{4}-\mathrm{P}$ is the highest among all nutrients. Further studies should compare the effects of CRF and LF on the nighttime $\mathrm{PO}_{4}-\mathrm{P}$ concentration in xylem exudates.

Therefore, the differences in nutrient uptake between the CRF- and LF-treated plants may be mainly attributed to the differences in the later stages. The difference in mineral concentrations of the CRF and LF substrate solutions may be the major factor. After harvesting of fruits from the first truss, EC values and inorganic mineral concentrations were much lower in the CRF substrate solution than in the LF substrate solution. In the CRF treatment, all the inorganic minerals were maintained near the 
threshold uptake level (i.e., minimum level required for a normal uptake) reported by Hosoi and Hosono (2005). These trends are in agreement with our previous results (Kinoshita et al., 2010a, 2010b). On the other hand, mineral concentrations in the CRF-treated xylem exudates after the harvesting of fruits from the first truss were much higher than the mineral concentrations in the substrate solution, similar to those observed for the LF treatment until the period of stem topping, as mentioned previously. Furthermore, the CRF- and LF-treated plants did not show any symptoms of nutritional deficiency. Therefore, plants in both of the treatment groups were thought to absorb sufficient minerals for healthy growth. These results emphasize the possibility that the plants barely absorbed any minerals from the substrate solution and, instead, absorbed the bulk of the minerals immediately after their release from the CRF surface after fruit harvesting from the first truss, as stated by Kinoshita et al. (2010b). Thus, nutrient supply with CRF was quantitatively controlled and restricted, depending on the substrate temperature, whereas that with LF was always plentiful because of the given mineral concentrations in the nutrient solution. In general, quantitative nutrient control in the closed hydroponics system reduces nutrient uptake to a greater extent than does EC-based control without reducing the fruit yields, as observed for tomato (Matsuda et al., 2010; Nakano et al., 2006, 2010) and melon (Pardossi et al., 2002). Hence, the lower mineral concentrations in xylem exudates of the CRF plants during the later growth stages may be caused by quantitative and restricted nutrient supply. Furthermore, the fact that the fertilizer particle surface in the CRF treatment remains completely surrounded by plant roots should be considered. This distribution of plant roots around fertilizer particles should be the subject of future research.

In the case of LF, high mineral concentrations in the substrate solution may lead to high mineral concentrations (except for $\mathrm{PO}_{4}-\mathrm{P}$ ) in the xylem exudates during the later stages, because mineral concentrations in the xylem exudates reflect nutrient availability in the rhizosphere (Noguchi et al., 2005). Furthermore, mineral concentrations in xylem exudates may increase during later growth stages because of the reduction in fruit number after stem topping above the 15th truss, which is consistent with the increase in $\mathrm{NO}_{3}-\mathrm{N}, \mathrm{Ca}$, and $\mathrm{Mg}$ concentrations in the xylem exudates after fruit removal (Masuda and Nomura, 1995). Therefore, reduction in the concentration of the fertilizer solution during the later stages of LF treatment may be an effective way of suppressing the increase in mineral concentrations of the substrate solution and luxury nutrient uptake.

On the other hand, $\mathrm{N}$ and $\mathrm{K}$ uptake in $\mathrm{CRF}$ plants may be greater than that in LF plants in the early growth stages, because the concentrations of $\mathrm{NO}_{3}-\mathrm{N}, \mathrm{NH}_{4}-\mathrm{N}$, and $\mathrm{K}$ in the xylem exudates were higher with CRF than with LF. Actually, the stem diameter, an indicator of plant growth, in the lower trusses was larger with CRF than with LF. Thus, nutrient supply in the early growth stage should be decreased to an even greater extent when CRF is applied to the system.

In conclusion, compared with LF, CRF was able to maintain the same fruit production with high nutrient utilization efficiency by suppressing luxury nutrient uptake. The difference in the level of luxury nutrient uptake between CRF and LF may be predominantly attributable to the differences in the later stages of the experiment. Furthermore, it appears that the plants absorbed the bulk of the minerals immediately after the nutrients were released from the CRF surface in the second half of the experiment, indicating that the fertilizer particle surface was completely surrounded by plant roots. Therefore, fertilizer use in tomato cultivation can be dramatically reduced by introducing CRF, because nutrients are absorbed efficiently and nutrient leaching is eliminated.

\section{Literature Cited}

Armstrong, M.J. and E.A. Kirkby. 1979. Estimation of potassium recirculation in tomato plants by comparison of the rates of potassium and calcium accumulation in the tops with their fluxes in the xylem stream. Plant Physiol. 63:11431148 .

Goodwin, P.B., M. Murphy, P. Melville, and W. Yiasoumi. 2003. Efficiency of water and nutrient use in containerized plants irrigated by over head, drip or capillary irrigation. Aust. J. Exp. Agr. 43:189-194.

Ho, L.C., R. Belda, M. Brown, J. Andrews, and P. Adams. 1993. Uptake and transplant of calcium and the possible causes of blossom-end rot in tomato. J. Expt. Bot. 44:509-518.

Hosoi, N. and T. Hosono. 2005. Liquid cultivation of tomato plants by daily control of fertilizer application in which there are no $\mathrm{N} / \mathrm{P} / \mathrm{K}$ residues in the culture solution and the area of leaf groups is used as an indicator. Bul. Natl. Inst. Veg. \& Tea Sci. 4:87-119 [in Japanese with English summary].

Imano, H., M. Masuda, and K. Murakami. 2011. Tomato cultivation by placing controlledrelease fertilizers on the wick in the root-proof capillary watering system. Hort. Res. (Jpn) 10:41-47 [in Japanese with English summary].

Incrocci, L., F. Malorgio, A. Della Bartola, and A. Pardossi. 2006. The influence of drip irrigation or subirrigation on tomato grown in closedloop substrate culture with saline water. Sci. Hort. 107:365-372.

Kinoshita, T. and M. Masuda. 2011. Effects of various substrates on growth and fruit yield in tomato forcing culture using a root-proof capillary wick. Hort. Res. (Jpn) 10:197-202 [in Japanese with English summary].

Kinoshita, T., M. Masuda, S. Watanabe, and Y. Nakano. 2010a. Application of controlled-release fertilizer to forcing culture of tomato using rootproof capillary wick. Hort. Res. (Jpn) 9:39-46 [in Japanese with English summary].

Kinoshita, T., S. Watanabe, Y. Nakano, and M. Masuda. 2010b. Comparison of the effect of controlled release fertilizer and liquid fertilizers on fruit yield and nutrient dynamics in root-proof capillary wick watering system for tomato culture. 28th International Horticultural Congress Abstracts. Vol.1. p. 36.

Ma, Q., T. Yamaguchi, N. Nakata, T. Nakano, T. Tanaka, and J. Nakano. 2005. Evaluation of root activity by bleeding exudates from the basal stem in soybean plants under excessive soil water. Root Res. 14:3-8 [in Japanese with English summary].
Masuda, M. 1989. Mineral concentrations in xylem exudates of tomato and cucumber plants at midday and midnight. J. Jpn. Soc. Hort. Sci. 58:619625 [in Japanese with English summary]

Masuda, M. 2008. Innovative cultivation method using capillary wick covered with water permeable root-barrier material. Agr. Hort. 83:20-25 [in Japanese].

Masuda, M. and S. Fukumoto. 2008. Potential for tomato cultivation using capillary wick-watering method. Sci. Rpt. Faculty. Agr. Okayama Univ. 97:49-54 [in Japanese with English summary].

Masuda, M. and K. Gomi. 1982. Diurnal change of the exudation rate and the mineral concentration in xylem exudates after decapitation of grafted and non grafted cucumbers. J. Jpn. Soc. Hort. Sci. 51:293-298.

Masuda, M. and M. Nomura. 1995. Change in mineral uptake and oxygen consumption by tomato roots as affected by pinching and fruit removal. J. Jpn. Soc. Hort. Sci. 64:73-78 [in Japanese with English summary].

Masuda, M. and Y. Shimada. 1993. Diurnal changes in mineral concentrations of xylem exudates in tomato plants and their concentrations as affected by sunlight intensity and plant ages. J. Jpn. Soc. Hort. Sci. 61:839-845 [in Japanese with English summary].

Matsuda, R., K. Suzuki, Y. Nakano, H. Sasaki, and M. Takaichi. 2010. Daily based quantitative nutrient management in rockwool hydroponics: Growth and yield of tomato and nutrient use at elevated $\mathrm{CO}_{2}$. J. Agr. Meteorol. 66:217-226.

Morishige, A., M. Masuda, and K. Murakami. 2009a. Large-fruited tomato production as affected by root-zone extension and wick addition during cultivation in a capillary wick system. Sci. Rpt. Faculty. Agr. Okayama Univ. 98:2329 [in Japanese with English summary].

Morishige, A., M. Masuda, and K. Murakami. 2009 b. Fruit vegetable cultivation for balance in demand and supply of nutrient and water using capillary wick covered with water permeable root-barrier material. VIII. Growth and fruit yield of large-fruited tomato subjected to different strengths of nutrient solution for longterm forcing culture. Hort. Res. (Japan) 8(suppl 1):360 (abstract).

Nakano, Y., H. Sasaki, A. Nakano, K. Suzuki, and M. Takaichi. 2010. Growth and yield of tomato plants as influenced by nutrient application rates with quantitative control in closed rockwool cultivation. J. Jpn. Soc. Hort. Sci. 79: $47-55$.

Nakano, Y., S. Watanabe, H. Kawashima, and M. Takaichi. 2006. The effect of daily nutrient applications on yield, fruit quality, and nutrient uptake of hydroponically cultivated tomato. J. Jpn. Soc. Hort. Sci. 75:421-429 [in Japanese with English summary].

Noguchi, A., M. Kageyama, F. Shinmachi, Urs. Schmidhalter, and I. Hasegawa. 2005. Potential for using plant xylem exudates to evaluate inorganic nutrient availability in soil. I. Influence of inorganic nutrients present in the rhizosphere on those in the xylem exudates of Luffa cylindrical Roem. Soil Sci. Plant Nutr. 51:333-341

Pardossi, A., P. Malorgio, L. Incrocci, C.A. Campiotti, and F. Tognoni. 2002. A comparison between two methods to control nutrient delivery to greenhouse melons grown in recirculating nutrient solution culture. Sci. Hort. 92: 89-95.

Sakaigaichi, T., S. Morita, J. Abe, and T. Yamaguchi. 2005. Serial change of nitrogen uptake after topdressing for rice plants. Jpn. J. Crop. Sci. 74: 285-290 [in Japanese with English summary]. 
Sakaigaichi, T., S. Morita, J. Abe, and T. Yamaguchi. 2007. Diurnal and phonological changes in the rate of nitrogen transportation monitored by bleeding in field-grown rice plants (Oryza sativa L.). Plant Prod. Sci. 10:270-276.

Santamaria, P., G. Campanile, A. Parente, and A. Elia. 2003. Subirrigation vs drip-irrigation: Effects on yield and quality of soilless grown cherry tomato. J. Hort. Sci. Biotechnol. 78: 290-296.

Tachibana, S. and I. Suzuki. 1980. Studies on the fertilization and cultivation of horticultural crops under covering conditions. VI. Effects of the concentration of nutrient solution on the chemical constituents in the root exudates of cucumber and tomato. Bul. Fac. Agr. Mie Univ. 60:1-13.

Terabayashi, S., K. Takii, and T. Namiki. 1991a. Variation in diurnal uptake of water and nutrients by tomato plants of different growth stages grown in water culture. J. Jpn. Soc. Hort. Sci. 59:751-755.

Terabayashi, S., K. Takii, and T. Namiki. 1991b. Variation in diurnal uptake of water and nutrients by tomato plants grown hydroponically. J. Jpn. Soc. Hort. Sci. 60:547-553.
Widders, I.E. and O.A. Lorenz. 1982. Ontogenetic changes in potassium transport in xylem of tomato. Physiol. Plant. 56:458-464.

Yamaguchi, T., Y. Tsuno, J. Nakano, and R. Mano. 1995. Analysis of factors concerning bleeding rate from the basal part of stem in rice plants. Jpn. J. Crop. Sci. 64:703-708 [in Japanese with English summary]

Yamasaki, A. 2003. Root-pressure driven xylem exudates flow in greenhouse melon (Cucumis melo L.): Diurnal change and effects of shading, growth stage, rootstock and fruit number. Plant Soil 255:409-412. 